\title{
Conservação de folículos pré-antrais bovinos em solução salina $0,9 \%$ ou TCM 199
}

[Preservation of bovine preantral follicles in 0.9\% saline solution or TCM 199]

\author{
J.J.H. Celestino ${ }^{1}$, R.R. Santos ${ }^{2}$, F.S. Martins ${ }^{2}$, M.H.T. Matos $^{2}$, J.R. Figueiredo ${ }^{2}$ \\ S.H.F. Costa ${ }^{2}$, J.R.V. Silva ${ }^{3}$, A.P.R. Rodrigues ${ }^{2}$ \\ ${ }^{1}$ Aluna de pós-graduação - FAVET-UECE - Fortaleza, CE \\ ${ }^{2}$ Faculdade de Veterinária - UECE \\ Av. Paranjana, 1700 \\ 60740-000 - Fortaleza, CE \\ ${ }^{3}$ Universidade Federal do Ceará - Fortaleza, CE
}

\begin{abstract}
RESUMO
Investigou-se a eficiência da solução salina $0,9 \%$ (SS) e TCM 199 na conservação de folículos pré-antrais (FOPA) bovinos in situ em diferentes temperaturas e tempos de incubação. Cada par ovariano foi dividido em 25 fragmentos. Um fragmento foi escolhido aleatoriamente e fixado imediatamente após a coleta (controle). Os demais foram distribuídos em tubos contendo SS ou TCM 199 a 4, 20 ou $39^{\circ} \mathrm{C}$ por 2 , 4,12 ou $24 \mathrm{~h}$. A análise histológica mostrou que a conservação a $4^{\circ} \mathrm{C}$ em ambas as soluções manteve a porcentagem de FOPA normais similar ao controle. A conservação em SS a $20^{\circ} \mathrm{C}$ por $12 \mathrm{ou} 24 \mathrm{~h}, \mathrm{TCM}$ 199 a $20^{\circ} \mathrm{C}$ por $24 \mathrm{~h}$ e em ambas as soluções a $39^{\circ} \mathrm{C}$ a partir de $2 \mathrm{~h}$ aumentou $(\mathrm{P}<0,05)$ a porcentagem de FOPA degenerados comparada à porcentagem de folículos-controle. Em ambas as soluções, independente do tempo de incubação, a porcentagem de folículos normais, após conservação a $39^{\circ} \mathrm{C}$, foi $(\mathrm{P}<0,05)$ menor que a obtida com 4 e $20^{\circ} \mathrm{C}$. FOPA bovinos podem ser conservados eficientemente a $4^{\circ} \mathrm{C}$ por até $24 \mathrm{~h}$ em ambas as soluções, e a $20^{\circ} \mathrm{C}$ por 4 e $12 \mathrm{~h}$ em SS e TCM 199, respectivamente.
\end{abstract}

Palavras-chave: bovino, folículo pré-antral, preservação

\begin{abstract}
The efficiency of 0.9\% saline solution (SS) and TCM 199 on the preservation of bovine preantral follicles $(P F)$ in situ at different temperatures and incubation times was investigated. Each ovarian pair was divided into 25 fragments. One fragment was taken randomly and immediately fixed (control). The other fragments were distributed in tubes containing SS or TCM 199 at 4, 20 or $39^{\circ} \mathrm{C}$ for 2, 4, 12 or 24 h. The histological analysis showed that the storage at $4^{\circ} \mathrm{C}$ in both solutions kept the percentage of normal follicles similar to control values. Preservation in SS at $20^{\circ} \mathrm{C}$ for 12 or $24 \mathrm{~h}, \mathrm{TCM} 199$ at $20^{\circ} \mathrm{C}$ for $24 \mathrm{~h}$ and in both solutions at $39^{\circ} \mathrm{C}$ from $2 \mathrm{~h}$ onward $(P<0.05)$ increased the percentage of degenerated follicles when compared with control. In both solutions, independent of incubation time, the percentage of normal follicles observed at $39^{\circ} \mathrm{C}$ was $(P<0.05)$ lower them those observed at 4 and $20^{\circ} \mathrm{C}$. Bovine $P F$ can be preserved efficiently at $4^{\circ} \mathrm{C}$ for up to $24 \mathrm{~h}$ in both solutions, at $20^{\circ} \mathrm{C}$ for 4 and $12 \mathrm{~h}$ in SS and TCM 199, respectively.
\end{abstract}

Keywords: bovine, preantral follicle, preservation

Recebido em 28 julho de 2005

Aceito em 26 de março de 2007

E-mail: juliana_jales@yahoo.com.br 


\section{Celestino et al.}

\section{INTRODUÇÃO}

Os folículos pré-antrais representam $90 \%$ da população folicular presente no ovário (Saumande, 1991). Na espécie bovina, o número de folículos por ovário pode variar de 0 a 720.000 (Erickson, 1966). As técnicas de isolamento folicular desenvolvidas para bovinos possibilitam a recuperação de cerca de 70.000 folículos pré-antrais por ovário (Bem et al., 1997). A utilização de oócitos provenientes de folículos pré-antrais em técnicas de reprodução assistida é uma excelente alternativa para a preservação e posterior propagação de animais valiosos e daqueles em vias de extinção. Entretanto, um fator limitante consiste na manutenção da qualidade folicular após remoção e transporte dos ovários, uma vez que, na maioria das vezes, esses animais encontram-se distantes dos laboratórios de reprodução. Além disso, é impossível a manipulação desses folículos isolados em curto período de tempo, afetando, dessa forma, a viabilidade antes do cultivo in vitro. Assim, o desenvolvimento de protocolos de conservação de folículos pré-antrais é muito importante para o sucesso da criopreservação e/ou cultivo folicular in vitro.

Os protocolos empregados para conservação de ovários têm utilizado meios de composição simples, como a solução salina $0,9 \%$, em bovinos (Solano et al., 1994; Lucci et al., 2004), ou complexa, como o TCM 199, em caprinos (Ferreira et al., 2001) e ovinos (Matos et al., 2004). O TCM 199 tem sido largamente empregado com sucesso no cultivo in vitro de embriões, oócitos oriundos de folículos antrais e pré-antrais, bem como na conservação de folículos pré-antrais caprinos e ovinos nas temperaturas de quatro e $20^{\circ} \mathrm{C}$. Entretanto, a influência do TCM 199 sobre a conservação de folículos pré-antrais bovinos ainda não foi testada.

O objetivo deste estudo foi investigar a eficiência da solução salina $0,9 \%$ e $\quad$ TCM 199 na conservação de folículos pré-antrais bovinos in situ em diferentes temperaturas $\left(4,20\right.$ ou $\left.39^{\circ} \mathrm{C}\right) \mathrm{e}$ tempos de incubação $(2,4,12$ ou $24 \mathrm{~h})$.

\section{MATERIAL E MÉTODOS}

Ovários $(\mathrm{n}=10)$ de cinco vacas adultas sem raça definida foram coletados em abatedouro local, imediatamente após o abate. Após a coleta, os ovários foram lavados uma vez em álcool a $70 \%$ por aproximadamente dez segundos e, em seguida, duas vezes em solução salina $0,9 \%$ e processados conforme descrito no protocolo experimental.

No abatedouro, os ovários oriundos de um mesmo animal foram divididos em 25 fragmentos de aproximadamente $9 \mathrm{~mm}^{3}$. Logo após a coleta, fixou-se, em Carnoy, um fragmento aleatoriamente escolhido para análise histológica dos folículos pré-antrais (controle não conservado). Distribuíram-se aleatoriamente os 24 fragmentos restantes em tubos estéreis ${ }^{1}$ de $15 \mathrm{ml}$, contendo $2 \mathrm{ml}$ de solução salina $0,9 \%$ ou TCM 199 e, em seguida, mantidos a 4, 20 ou $39^{\circ} \mathrm{C}$ por $2,4,12$ ou $24 \mathrm{~h}$. Mantiveram-se as temperaturas com auxílio de recipientes térmicos com água a 4,20 ou $39^{\circ} \mathrm{C}$. Após o período de conservação, realizaram-se a fixação e o processamento individual dos fragmentos para a histologia clássica. Cada tratamento foi repetido cinco vezes. Aferiu-se o $\mathrm{pH}$ dos meios de conservação no início (meio fresco) e término dos tempos de conservação.

Após o término do período de conservação, os fragmentos foram fixados em Carnoy por $12 \mathrm{~h}$, desidratados em séries gradativas de etanol, clarificados em xilol e embebidos em parafina. Seccionou-se o tecido ovariano seriadamente, em intervalos de sete micrômetros; as secções foram coradas pelo método PAS-hematoxilina. Nas secções examinadas com auxílio de um microscópio óptico ${ }^{2}$, consideraram-se somente os folículos pré-antrais que apresentassem núcleo do oócito visível. Avaliaram-se cerca de 155 folículos pré-antrais por tratamento.

Os folículos pré-antrais foram classificados de acordo com o estádio de desenvolvimento em primordiais (oócito circundado por uma camada de célula da granulosa de formato pavimentoso) e em desenvolvimento (oócito circundado por uma ou mais camadas de células da granulosa de formato cúbico). A qualidade folicular baseou-se na morfologia do oócito (presença ou ausência de picnose nuclear ou retração citoplasmática), na organização das células da granulosa, bem como na presença ou ausência de picnose e

\footnotetext{
${ }^{1}$ Corning Glass Works, Corning, NY

${ }^{2}$ Zeiss, Germany
} 
integridade da membrana basal. De acordo com o oócito e as células da granulosa, classificaram-se os folículos como normais (oócito saudável e células da granulosa bem organizadas - Fig. 1a) ou degenerados do tipo 1 (oócito com núcleo picnótico, apresentando-se algumas vezes retraído - Fig. 1b) ou degenerados do tipo 2 (oócito degenerado e células da granulosa desorganizadas - Fig. 1c).
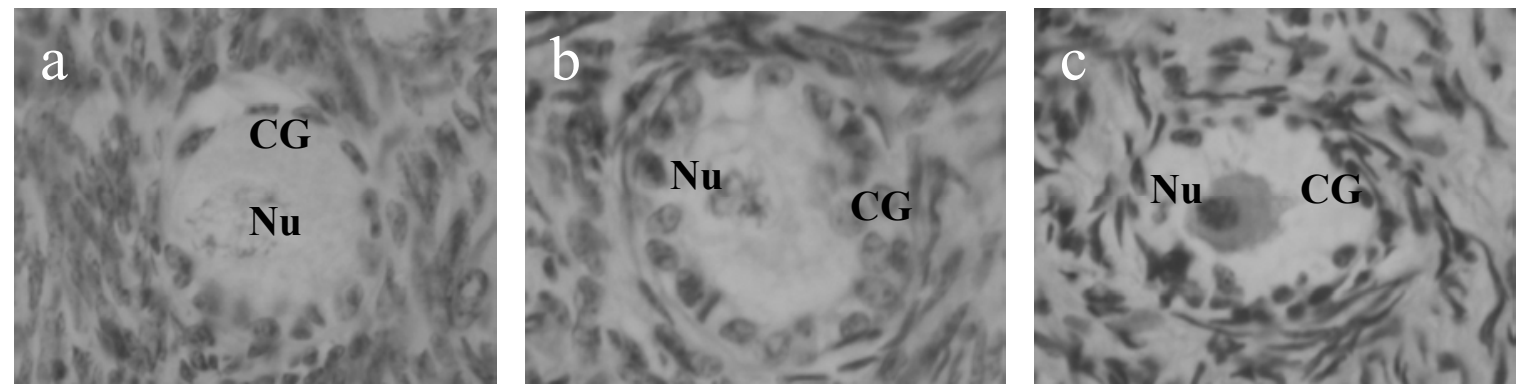

Figura 1. Secções histológicas de um folículo normal (a), folículo degenerado tipo 1 (b) e folículo degenerado tipo 2 (c), após conservação in situ. CG: células da granulosa, Nu: núcleo do oócito. Coloração PAS-hematoxilina (400x).

Os efeitos de solução (solução salina $0,9 \%$ e TCM 199), temperatura e tempo de incubação sobre a porcentagem de folículos normais e degenerados (tipo 1 e tipo 2), bem como sobre as diferentes classes foliculares (primordiais e em desenvolvimento), foram analisados pelo teste qui-quadrado $(\mathrm{P}<0,05)$.

\section{RESULTADOS}

Analisaram-se 3881 folículos pré-antrais (cerca de 155 folículos por tratamento). A porcentagem de folículos normais, conservados em solução salina $0,9 \%$ a $4^{\circ} \mathrm{C}$ por $24 \mathrm{~h}$ e $20^{\circ} \mathrm{C}$ por $4 \mathrm{~h}$, foi similar $(\mathrm{P}>0,05)$ à de folículos do grupocontrole. No entanto, a conservação em solução salina a $20^{\circ} \mathrm{C}$ por 12 ou $24 \mathrm{~h}$ e a $39^{\circ} \mathrm{C}$ por $2 \mathrm{~h}$ ou mais reduziu $(\mathrm{P}<0,05)$ a porcentagem de folículos normais em relação aos folículoscontrole. Resultados similares foram obtidos quando o TCM 199 foi utilizado, exceto para o tratamento em que os fragmentos ovarianos foram incubados a $20^{\circ} \mathrm{C}$ por $12 \mathrm{~h}$, isto é, a porcentagem de folículos normais foi similar $(\mathrm{P}>0,05)$ à de folículos-controle (Fig. 2).

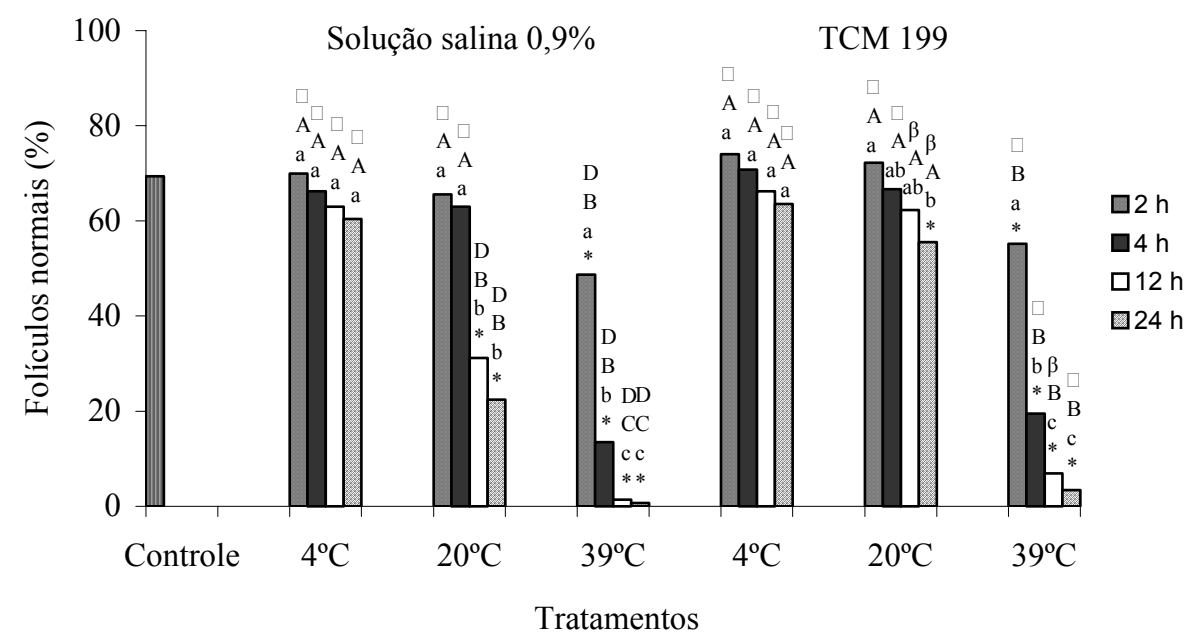

Figura 2. Efeito da temperatura e tempo de conservação sobre a porcentagem de folículos pré-antrais morfologicamente normais, conservados em solução salina 0,9\% e TCM 199.

*Diferem estatisticamente do controle $(\mathrm{P}<0,05)$. Letras distintas, maiúsculas no mesmo tempo de incubação e minúsculas na mesma temperatura, indicam diferença $(\mathrm{P}<0,05)$; letras gregas distintas entre os meios, nas mesmas temperatura e tempo de incubação, indicam diferença $(\mathrm{P}<0,05)$. 


\section{Celestino et al.}

O efeito do tempo de incubação foi analisado em cada temperatura e em cada meio de conservação. Em ambas as soluções, não foi observado efeito do tempo de conservação ao se utilizar a temperatura de $4^{\circ} \mathrm{C}$. No entanto, a conservação em solução salina a $20^{\circ} \mathrm{C}$ promoveu redução da porcentagem de folículos normais com o aumento do tempo de 4 para 12 ou $24 \mathrm{~h}$. Quanto ao TCM 199, essa diminuição foi observada apenas com o aumento do tempo de conservação de 2 para $24 \mathrm{~h}(\mathrm{P}<0,05)$. A redução $(\mathrm{P}<0,05)$ da porcentagem de folículos pré-antrais normais ocorreu com o aumento do tempo de incubação de 2 para 4, 12 e $24 \mathrm{~h}$, em ambas as soluções a $39^{\circ} \mathrm{C}$.

Com relação ao efeito da temperatura em um mesmo período de incubação, nos tempos de conservação de 12 e $24 \mathrm{~h}$, foi observado que, em solução salina a $20^{\circ} \mathrm{C}$, a porcentagem de folículos normais reduziu-se quando comparada à porcentagem de folículos normais em solução a $4^{\circ} \mathrm{C}$. Independentemente do tempo de incubação em ambas as soluções, o percentual de folículos morfologicamente normais observado a $39^{\circ} \mathrm{C}$ foi significativamente inferior $(\mathrm{P}<0,05)$ ao percentual observado após conservação a 4 e $20^{\circ} \mathrm{C}$.

Ao se comparar a solução salina $0,9 \%$ com TCM 199 em uma mesma temperatura e em um mesmo tempo de incubação (efeito de meio), não foram observadas diferenças $(\mathrm{P}<0,05)$ na porcentagem de folículos pré-antrais normais a $4^{\circ} \mathrm{C}$ entre todos os períodos de incubação testados. Entretanto, foi observada porcentagem $(\mathrm{P}<0,05)$ mais alta de folículos normais em TCM 199 conservados a $20^{\circ} \mathrm{C}$ por 12 e $24 \mathrm{~h}$ e a $39^{\circ} \mathrm{C}$ por $12 \mathrm{~h}$

Na Fig. 3 mostra-se a distribuição de folículos pré-antrais degenerados tipo 1 e tipo 2 no controle e nos diferentes tratamentos após conservação em solução salina (Fig. 3a) e em TCM 199 (Fig. 3b). Predominância $(\mathrm{P}<0,05)$ de folículos degenerados tipo 1 foi encontrada no controle e após conservação em solução salina a $4^{\circ} \mathrm{C}$ por 2,4 e $24 \mathrm{~h}$, a $20^{\circ} \mathrm{C}$ por 4 e $24 \mathrm{~h}$, e em TCM 199 a $4^{\circ} \mathrm{C}$ em todos os tempos de incubação, bem como a $20^{\circ} \mathrm{C}$ por 2,4 e $24 \mathrm{~h}$. Em contraste, maiores porcentagens $(\mathrm{P}<0,05)$ de folículos degenerados tipo 2 foram observadas após conservação em ambas as soluções a $39^{\circ} \mathrm{C}$ em todos os tempos de incubação, exceto nos fragmentos estocados em TCM 199 por 2 e $4 \mathrm{~h}$.

Quando comparado ao grupo-controle, observouse maior porcentagem de folículos degenerados tipo 1 em solução salina $0,9 \%$ a $20^{\circ} \mathrm{C}$ por 12 e $24 \mathrm{~h}$, e em TCM 199 a $20^{\circ} \mathrm{C}$ por $24 \mathrm{~h}$ e a $39^{\circ} \mathrm{C}$ por 4, 12 e $24 \mathrm{~h}$. Quanto aos folículos degenerados tipo 2, comparado aos folículos-controle, encontrou-se percentual $(\mathrm{P}<0,05)$ mais alto em folículos conservados em solução salina $0,9 \%$ a $20^{\circ} \mathrm{C}$ por 12 e $24 \mathrm{~h}$ e a $39^{\circ} \mathrm{C}$ em todos os tempos de incubação, e em TCM 199 a $20^{\circ} \mathrm{C}$ por $12 \mathrm{~h}$ e a $39^{\circ} \mathrm{C}$ em todos os tempos de incubação.

$\mathrm{Na}$ Fig. 4 mostram-se as porcentagens de folículos primordiais e em desenvolvimento morfologicamente normais no grupo-controle e após conservação em solução salina $0,9 \%$ (Fig. 4a) ou TCM 199 (Fig. 4b). Em ambos os meios testados, observou-se que, nas temperaturas mais baixas $\left(4\right.$ e $\left.20^{\circ} \mathrm{C}\right)$ e por um curto período de incubação (2 e 4h), os folículos em desenvolvimento mostraram-se $(\mathrm{P}<0,05)$ mais resistentes ao resfriamento quando comparados aos folículos primordiais. A $39^{\circ} \mathrm{C}$, não foi observada diferença $(\mathrm{P}<0,05)$ entre as duas classes foliculares, excetuando-se quando os folículos foram mantidos em solução salina $0,9 \%$ por $4 \mathrm{~h}$ e em TCM 199 por 12h, quando a porcentagem $(\mathrm{P}<0,05)$ de folículos em desenvolvimento foi mais baixa em relação à de folículos primordiais.

\section{DISCUSSÃO}

A morfologia dos folículos pré-antrais bovinos pode manter-se normal durante a conservação ao se utilizar tanto da solução salina quanto do TCM 199. Entretanto, a eficiência de cada meio de conservação depende da temperatura e do tempo de incubação. 
(a)

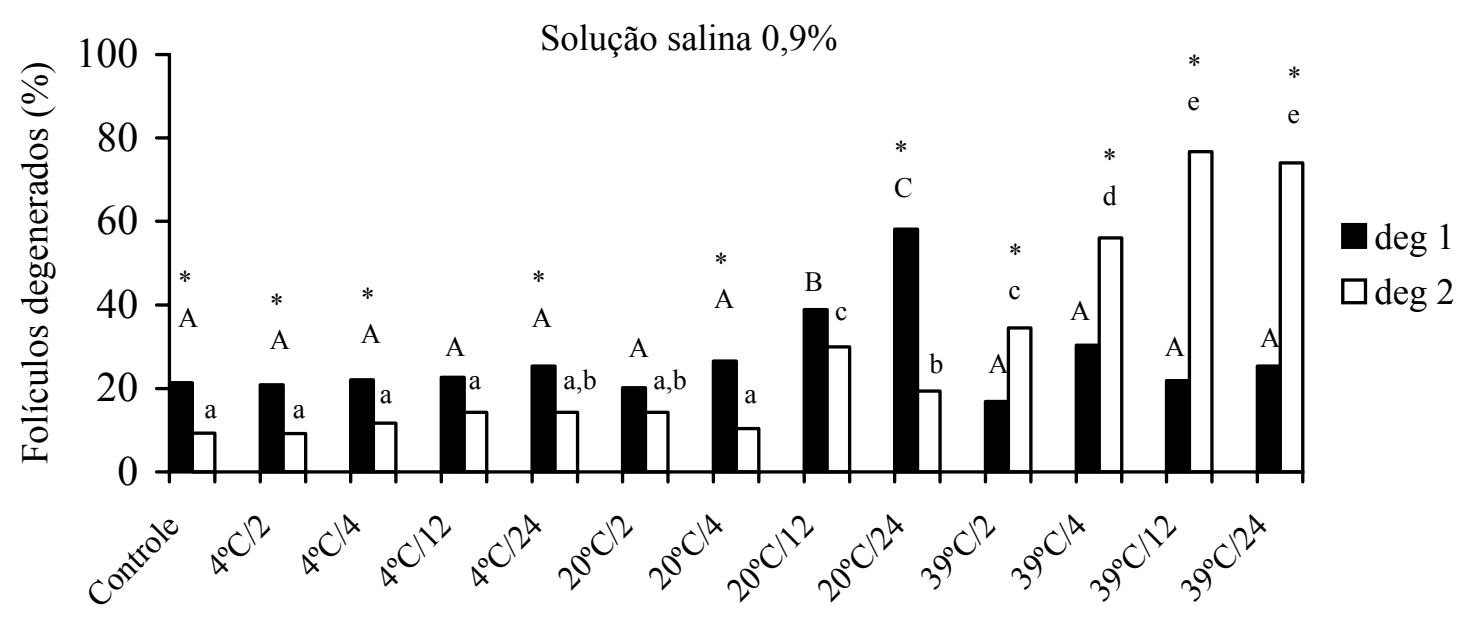

Temperatura/Hora

(b)

TCM 199

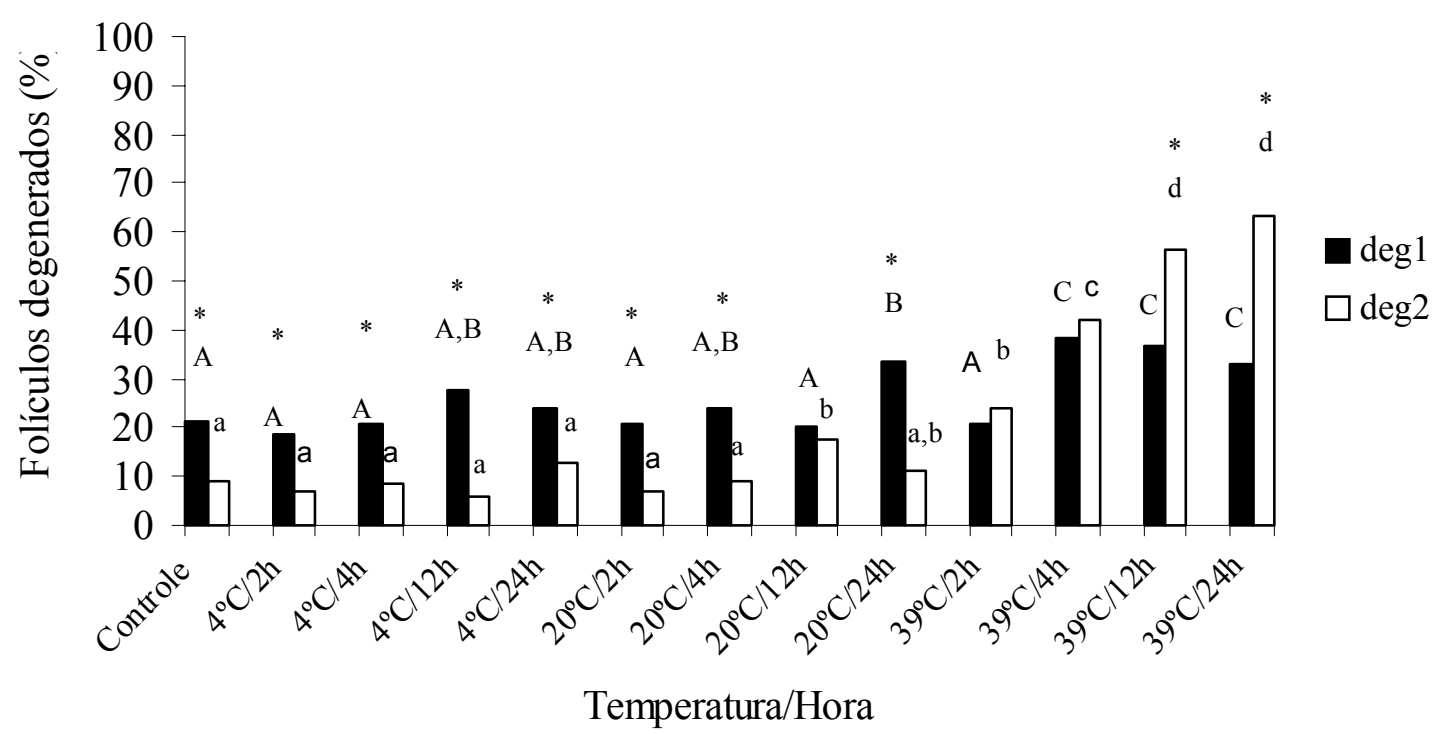

Figura 3. Distribuição da porcentagem de folículos pré-antrais degenerados do tipo 1 (deg. 1) e tipo 2 (deg. 2) no controle e após conservação em diferentes tratamentos, em solução salina $0,9 \%$ (a) e em TCM 199 (b).

*Diferença entre os tipos de folículos degenerados em cada tratamento $(\mathrm{P}<0,05)$; Letras distintas maiúsculas indicam diferença na porcentagem de folículos degenerados tipo 1 e minúsculas na porcentagem de folículos degenerados tipo 2 , entre os tratamentos $(\mathrm{P}<0,05)$. 


\section{Celestino et al.}

(a)

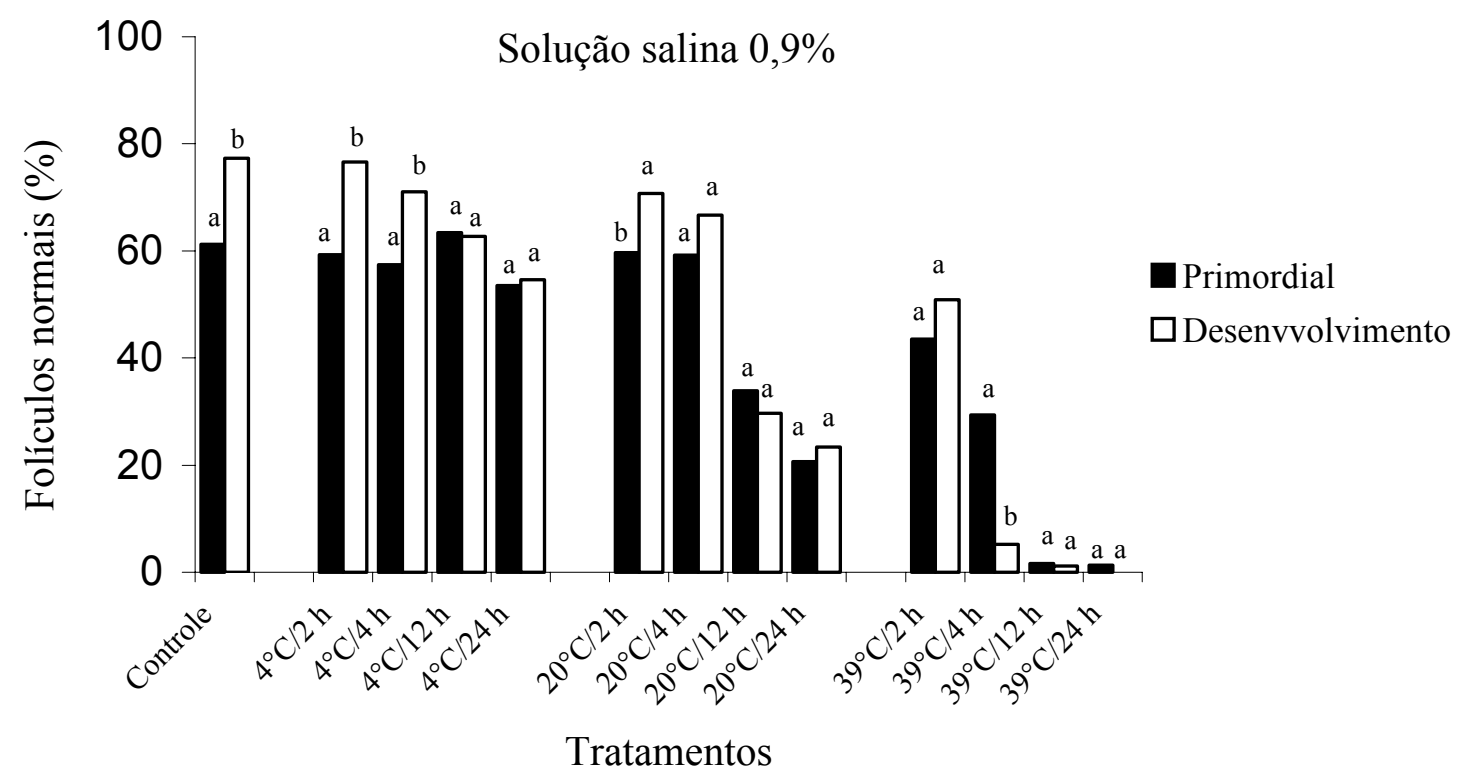

(b)

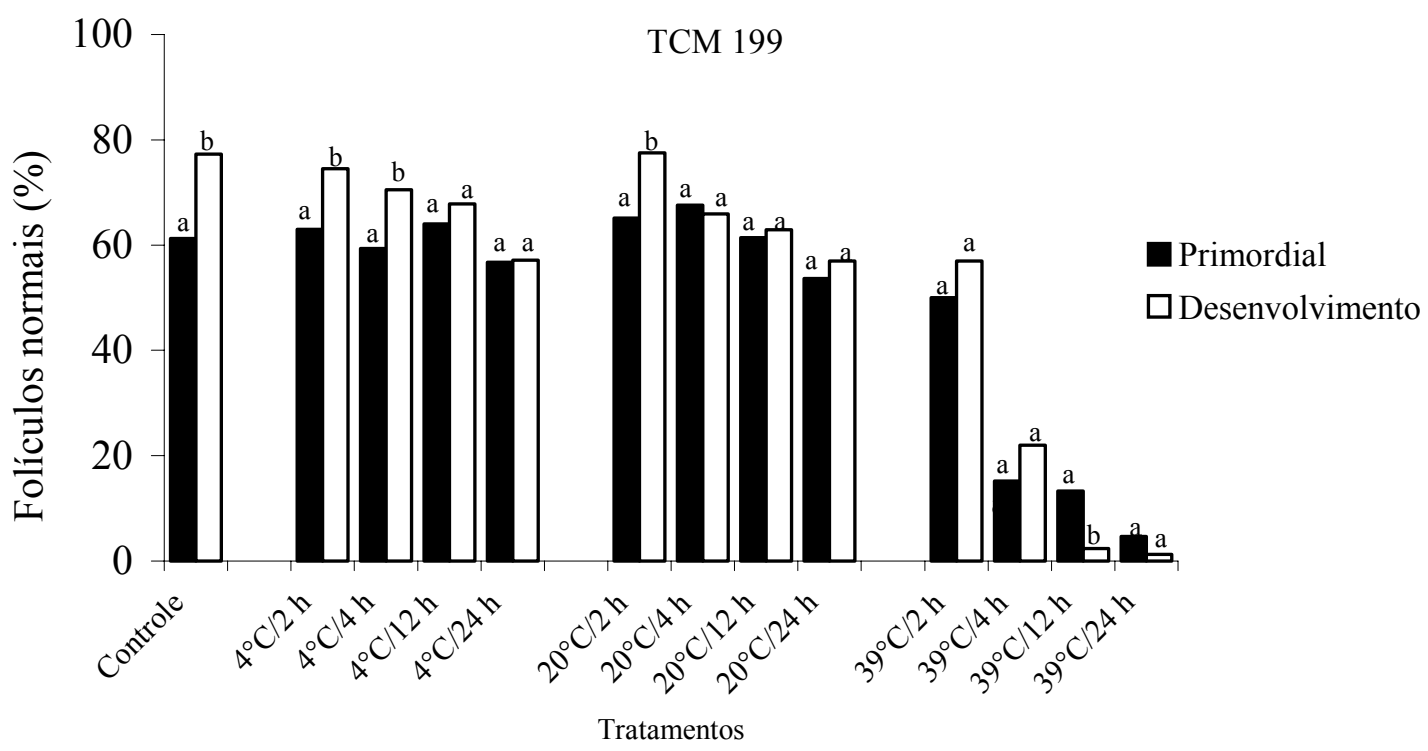

Figura 4. Porcentagem de folículos primordiais e em desenvolvimento morfologicamente normais no controle e após conservação em solução salina 0,9 \% (a) e em TCM 199 (b) em diferentes temperaturas e tempos de incubação.

Letras distintas indicam diferença na porcentagem de folículos normais encontrada em cada tratamento $(\mathrm{P}<0,05)$. 
A conservação de fragmentos ovarianos a $4{ }^{\circ} \mathrm{C}$ por até $24 \mathrm{~h}$ manteve a porcentagem de folículos pré-antrais normais similar à de folículoscontrole, independente do meio utilizado. Foi demonstrado, em pequenos ruminantes, que a temperatura de $4^{\circ} \mathrm{C}$ pode ser utilizada com sucesso na conservação de foliculos pré-antrais, por até $24 \mathrm{~h}$, em soluções simples, como a solução salina $0,9 \%$ em caprinos (Carvalho et al., 2001; Costa et al., 2002) e ovinos (Andrade et al., 2001), em soluções ricas em nutrientes, como o TCM 199, também em caprinos (Ferreira et al., 2001) e ovinos (Andrade et al., 2002; Matos et al., 2004) ou em soluções hiperosmóticas, como a solução Braun-Collins em caprinos (Silva et al., 2000). Roy e Treacy (1993) observaram que as baixas taxas metabólicas, causadas pelas baixas temperaturas, são essenciais para a manutenção da viabilidade de folículos préantrais humanos após isolamento, devido à diminuição do metabolismo celular e, conseqüentemente, à redução da necessidade metabólica. Schmidt et al. (2003) relataram a sobrevivência de folículos primordiais humanos, após transporte a $0^{\circ} \mathrm{C}$ por $4 \mathrm{~h}$. Quanto à conservação de ovários bovinos, Lucci et al. (2004) observaram porcentagem de folículos normais similar à de folículos-controle, quando conservados em solução à base de água de coco a $4^{\circ} \mathrm{C}$ por até $18 \mathrm{~h}$.

Quando folículos pré-antrais foram estocados a $20^{\circ} \mathrm{C}$ por até 4 e $12 \mathrm{~h}$ em solução salina e TCM 199, respectivamente, a porcentagem de folículos pré-antrais normais não diferiu daquela observada no controle. Resultados similares foram observados com a conservação de folículos pré-antrais ao utilizar TCM 199 para a espécie caprina (Ferreira et al., 2001) e ovina (Matos et al., 2004) e solução salina 0,9\% também para caprinos (Costa et al., 2002) e ovinos (Andrade et al., 2002). A temperatura de $39^{\circ} \mathrm{C}$ reduziu a porcentagem de folículos bovinos após conservação por $2 \mathrm{~h}$. Estes resultados diferem daqueles descritos por Matos et al. (2004), que trabalharam com ovelhas, nas quais foi mantida a porcentagem de folículos normais similar a do grupo-controle, após duas horas de conservação em solução salina 0,9\% e TCM 199. Isso pode ser devido a diferenças entre as espécies bem como ao tipo de folículo pré-antral empregado na conservação, pois os referidos autores trabalharam exclusivamente com folículos primordiais, que são mais resistentes, por serem metabolicamente menos ativos. O metabolismo normal $\left(39^{\circ} \mathrm{C}\right)$ ou subnormal $\left(20^{\circ} \mathrm{C}\right)$, associado à baixa tensão de oxigênio em estudos in vitro, pode resultar em taxas de degeneração folicular, como as observadas nos fragmentos ovarianos estocados a $20^{\circ} \mathrm{C}$ e $39^{\circ} \mathrm{C}$. Jennings et al. (1975) sugeriram que mudanças na permeabilidade da membrana celular, induzida pela falta de oxigênio, causam mudanças no nível intracelular de íons $\mathrm{Na}^{+}, \mathrm{K}^{+} \mathrm{e}$ $\mathrm{Cl}^{-}$, que estão associados às mudanças na distribuição de $\mathrm{Ca}^{++}$e ao aumento da água intracelular. Tal fato leva ao aumento do volume celular e conseqüentemente à degeneração celular.

Neste estudo, o TCM 199 foi mais eficiente que a solução salina $0,9 \%$ na conservação de folículos pré-antrais bovinos a $20^{\circ} \mathrm{C}$ por 12 e 24 h. Os folículos pré-antrais utilizam nutrientes de duas fontes, uma é seu próprio estoque endógeno e outra, o meio de conservação utilizado (Santos et al., 2002). Com isso, a $4^{\circ} \mathrm{C}$ (em todos os períodos de incubação) e a $20^{\circ} \mathrm{C}$ (por até $4 \mathrm{~h}$ ), folículos pré-antrais bovinos foram capazes de sobreviver com suas reservas energéticas, pois, os meios tiveram eficácia similar. Entretanto, com o aumento do tempo e da temperatura de incubação, a composição do meio passou a ser um fator importante para a manutenção da viabilidade folicular, pois, com o aumento do metabolismo, aumenta conseqüentemente o consumo dos nutrientes do meio. Os melhores resultados observados a altas temperaturas e por longo período de conservação utilizando TCM 199 foram, provavelmente, devido à riqueza em nutrientes, como, por exemplo, sais inorgânicos, glicose, vitaminas e aminoácidos (Migliorisi et al., 1987). Efeito similar foi demonstrado na conservação de folículos de pré-antrais ovinos (Andrade et al., 2002).

A análise histológica mostrou predominância de folículos pré-antrais degenerados tipo 1 (degeneração somente no oócito) no controle bem como nos fragmentos estocados a 4 e $20^{\circ} \mathrm{C}$. Resultados similares foram obtidos com folículos pré-antrais frescos bovinos (Erickson, 1986), murinos (Hirshfield, 1988), caprinos (Bezerra et al., 1998; Lucci et al., 1999) e ovinos (Jorio et al., 1991), estocados a $4^{\circ} \mathrm{C}$ em felinos (Wood et al., 1997), caprinos (Ferreira et al., 2001; Silva et 


\section{Celestino et al.}

al., 2001) e ovinos (Andrade et al., 2001; Matos et al., 2004), bem como no cultivo de folículos pré-antrais bovinos (Figueiredo et al., 1994; Braw e Yossefi., 1997). Segundo Lucci et al. (2004), maior porcentagem de folículos degenerados tipo 1 foi encontrada no grupocontrole, bem como nos tratamentos que não diferiram dele. De acordo com Jorio et al. (1991), a degeneração do oócito é a maneira mais freqüente de atresia observada em folículos pré-antrais. Hirshfield (1983) também relatou que, nos folículos secundários com 75 a $150 \mu \mathrm{m}$ de diâmetro, a degeneração do oócito foi comumente o único sinal da atresia. Estudos in vitro também mostraram folículos pré-antrais com o oócito degenerado ou completamente desaparecido, em que as células da granulosa pareciam normais e continuavam a se proliferar, mostrando que o oócito é muito mais sensível aos eventos da degeneração que as células da granulosa (Figueiredo et al., 1994; Braw e Yossefi, 1997). Ao contrário, nos tratamentos em que os fragmentos foram conservados a $39^{\circ} \mathrm{C}$, foi mais comum a degeneração do tipo 2 , nos quais, além da degeneração do oócito, as células da granulosa encontravam-se desorganizadas e aumentadas de volume. Resultados similares foram obtidos por Silva et al. (2001) na preservação de folículos pré-antrais de cabras em solução Braun-Collins e solução à base de água de coco a $39^{\circ} \mathrm{C}$ por até $24 \mathrm{~h}$, e por Matos et al. (2004), na conservação de folículos primordiais ovinos em solução salina 0,9\% e TCM 199.

Com relação ao efeito das condições de conservação sobre as diferentes classes foliculares (primordiais e em desenvolvimento), foi observado que, nas temperaturas mais baixas (4 ou $20^{\circ} \mathrm{C}$ ), os folículos em desenvolvimento apresentaram-se mais resistentes que os folículos primordiais. Segundo Vanhoutte et al. (2004), oócitos circundados com duas ou três camadas de células da granulosa podem ser mais protegidos das injúrias causadas pelo frio. Além disso, os folículos em desenvolvimento já passaram pelo processo inicial de ativação folicular e possuem mais reservas nutritivas. No entanto, com o aumento da temperatura de incubação $\left(39^{\circ} \mathrm{C}\right)$, foi verificado que, com 4 e $12 \mathrm{~h}$ de incubação, os folículos em desenvolvimento foram mais susceptíveis à degeneração em solução salina 0,9\% e TCM 199, respectivamente. Isso pode ser atribuído ao fato de que, na temperatura de $39^{\circ} \mathrm{C}$, há aumento do metabolismo, dessa forma, os folículos em desenvolvimento necessitam de mais reservas nutricionais que os folículos primordiais que ainda se encontram quiescentes.

Em conclusão, este estudo mostrou que folículos pré-antrais bovinos podem ser conservados eficientemente a $4^{\circ} \mathrm{C}$ por até $24 \mathrm{~h}$ em ambas as soluções e a $20^{\circ} \mathrm{C}$ por 4 e $12 \mathrm{~h}$ em solução salina $0,9 \%$ e TCM 199, respectivamente. Entretanto, folículos pré-antrais bovinos, independentemente do meio utilizado, mostraram-se altamente susceptíveis à degeneração na temperatura de $39^{\circ} \mathrm{C}$, mesmo em um curto período de incubação. A susceptibilidade da categoria folicular (folículos primordiais e folículos em desenvolvimento) à atresia foi afetada de forma diferenciada pela temperatura de conservação, sendo os folículos primordiais e em desenvolvimento mais resistentes à atresia em altas $\left(39^{\circ} \mathrm{C}\right)$ e baixas $\left(4\right.$ e $\left.20^{\circ} \mathrm{C}\right)$ temperaturas, respectivamente. $\mathrm{O}$ uso desse protocolo de conservação poderá facilitar o transporte de folículos pré-antrais bovinos a laboratórios especializados em biotécnicas de reprodução animal, garantindo a manutenção da morfologia folicular, podendo esses folículos fornecer milhares de oócitos viáveis para o crescimento e maturação in vitro e, ainda, ser possível a formação de bancos de oócitos de animais valiosos e daqueles em via de extinção.

\section{AGRADECIMENTOS}

Os autores agradecem ao Dr. Vicente José de Figueirêdo Freitas e à sua equipe do Laboratório de Fisiologia e Controle da Reprodução da Universidade Estadual do Ceará pelo suporte técnico.

\section{REFERÊNCIAS BIBLIOGRÁFICAS}

ANDRADE, E.R.; AMORIM, C.A.; COSTA, S.H.F. et al. Preliminary study of short-term preservation of ovine ovarian tissue containing preantral follicles in saline solution or TCM 199. Vet. Rec., v.151, p.452-453, 2002.

ANDRADE, E.R.; AMORIM, C.A.; MATOS, M.H.T. et al. Evaluation of saline and coconut water solutions in the preservation of sheep preantral follicles in situ. Small Rumin. Res., v.43, p.235-243, 2002. 
ANDRADE, E.R.; RODRIGUES, A.P.R.; AMORIM, C.A. et al. Short term maintenance of sheep preantral follicles in situ $0.9 \%$ saline and Braun-Collins solution. Small Rumin. Res., v.41, p.141-149, 2001.

BEM, A.R.; LUCCI, C.M.; RODRIGUES, A.P.R. et al. Isolamento mecânico de folículos pré-antrais de ovários de vacas Nelore. In: REUNIÃO ANUAL DA SOCIEDADE BRASILEIRA DE TRANSFERÊNCIA DE EMBRIÕES, 12., 1997, Foz do Iguaçu. Anais... Foz do Iguaçu: SBTE, 1997. p.182 (Resumo).

BEZERRA, M.B.; RONDINA, D.; LIMA, A.K.F. et al. Aspectos quantitativos e qualitativos de foliculogênese na fase pré-natal na espécie caprina. Cien. Anim., v.8, p.4756, 1998.

BRAW-TAL, R.; YOSSEFI, S. Studies in vivo and in vitro on the initiation of follicle growth in the bovine ovary. J. Reprod. Fertil., v.109, p.165-171, 1997.

CARVALHO, F.C.A.; LUCCI, C.M.; SILVA. J.R.V. et al. Effect of Braun-Collins and saline solutions at different temperatures and incubation times on the quality of goat preantral follicles preserved in situ. Anim. Reprod. Sci., v.66, p.195-208, 2001.

COSTA, S.H.F.; SANTOS, R.R.; FERREIRA, M.A.L. et al. Preservation of goat preantral follicles in saline or coconut water solution. Braz. J. Vet. Res. Anim. Sci., v.39, p.324-30, 2002.

ERICKSON, G.F. An analysis of follicle development and ovum maturation. Sem. Reprod. Endocrinol., v.3, p.233-254, 1986 .

FERREIRA, M.A.L.; BRASIL, A.F.; SILVA, J.R.V. et al. Effects of storage time and temperature on atresia of goat ovarian preantral follicles held in M199, with or without índole-3-acetic acid suplementation. Theriogenology, v.55, p.1607-1617, 2001.

FIGUEIREDO, J.R.; HULSHOF, S.C.J.; VAN DEN HURK, R. et al. Preservation of oocyte and granulosa cell morphology in bovine preantral follicles cultured in vitro. Theriogenology, v.41, p.1333-1346, 1994.

HIRSHFIELD, A.N. Compensatory ovarian hypertrophy in the long term hemicastrate rat: size distribution of growing and atretic follicles. Biol. Reprod., v.28, p.271278, 1983.

HIRSHFIELD, A.N. Size frequency analysis of atresia in cycling rats. Biol. Reprod., v.38, p.1181-1188, 1988.

JENNINGS, R.B.; GANOTE, C.E.; REIMER, K.A. Ischemic tissue injury. Am. J. Pathol., v.81, p.179-197, 1975.

JORIO, A.; MARIANA, J.C.; LAHLOU-KASSI, A. Development of the population of ovarian follicles during the prepubertal period in D' man and Timahdite sheep. Anim. Reprod. Sci., v.26, p.239-250, 1991.
LUCCI, C.M.; AMORIM, C.A.; RODRIGUES, A.P.R. et al. Study of preantral follicle population in situ and after mechanical isolation from caprine ovaries at different reproductive stages. Anim. Reprod. Sci., v.56, p.223-236, 1999.

LUCCI, C.M.; KACINSKIS, M.A.; RUMPF, R. et al. Effects of lowered temperatures and media on short-term preservation of zebu (Bos indicus) preantral ovarian follicles. Theriogenology, v.61, p.461-472, 2004.

MATOS, M.H.T.; ANDRADE, E.R.; LUCCI, C.M. et al. Morphological and ultrastructural analysis of sheep primordial follicles preserved in $0.9 \%$ saline solution and TCM 199. Theriogenology, v.62, p.65-80, 2004.

MIGLIORISI, G.; FOLKES, E.; PAWLOWSKI, N. Human endothelial cells. Am. J. Pathol., v.127, p.157, 1987.

ROY, S,K.; TREACY, B.J. Isolation and long-term culture of human preantral follicles. Fertil. Steril., v.59, p.783-790, 1993.

SANTOS, R.R.; SILVA, J.R.V.; COSTA, S.H.F. et al. Effect of $0.9 \%$ saline solution and phosphate buffer saline at different temperatures and incubation times on the morphology of goat preantral follicles. Braz. J. Vet. Res. Anim. Sci. v.39, p.254-259, 2002.

SAUMANDE, J. La folliculogénèse chez les ruminants. Rec. Med. Vet., v.167, p.205-218, 1991.

SCHMIDT, K.L.T.; ERNST, E.; BYSKOV, A.G. et al. Survival of primordial follicles following prolonged transportation of ovarian tissue prior to cryopreservation. Hum. Reprod., v.18, p.2654-2659, 2003.

SILVA, J.R.V.; BÁO, S.N.; LUCCI, C.M. et al. Morphological and ultrastructural changes occurrig during degeneration of goat preantral follicles preserved in vitro. Anim. Reprod. Sci., v.66, p.209-223, 2001.

SILVA, J.R.V.; LUCCI, C.M.; CARVALHO, F.C.A. et al. Effect of coconut water and Braun-Collins solutions at different temperatures and incubation times on the morphology of goat preantral follicles preserved in vitro. Theriogenology, v.54, p.809-822, 2000.

SOLANO, R.; ARMAS. R.; PUPO, C.A. et al. Short term preservation of intrafollicular oocytes at $4{ }^{\circ} \mathrm{C}$. Theriogenology, v.41, p.299, 1994.

VANHOUTTE, L.; CORTVRINDT, R.; NOGUEIRA, D. et al. Effects of chilling on structral aspects of early preantral mouse follicles. Biol. Reprod., v.70, p.10411048, 2004.

WOOD, T.C.; MONTALI, R.J.; WILD, D.E. Follicleoocyte atresia and temporal taphonomy in cold-stored domestic cat ovaries. Mol. Reprod. Dev., v.46, p.190-200, 1997. 